\title{
SENSATIONS FROM NATURE
}

\author{
M.J. FRYER \\ 3, The Thrift, Bean, Dartford, Kent DA2 8BL, UK.
}

\begin{abstract}
Sensations from nature provoke an emotional response from a particular motif around which a painting is constructed. Nature is not slavishly copied but the sensations are submitted to the necessity of making a picture in which the compositional elements are brought into unity over the whole surface to achieve stability. Within the stability there are local areas of dissonance to add a dynamic structure to the composition and to attract the gaze as the painting is examined by very rapid eye movements (saccades). Examples are given of a number of paintings by the author comprising two abstracts and four landscapes. Colours are heightened and usually highly saturated, so that they have an intense purity to express the emotions with greatest clarity and may not be imitative. Each colour is put down in relation to all other colours with consideration for their interrelationships and expressiveness. Painting is instinctive but has an underlying theoretical basis relying on the juxtaposition and displacement of complementary colours and of dissonant colour. In order to demonstrate the methodology of painting, two series of 'progressive' images are given that show the completion of two additional landscapes in six stages.

Keywords: complementary, harmony, heightened colour, landscape paintings, Mike Fryer, saccades, stability.
\end{abstract}

\section{INTRODUCTION}

The paintings by the author described in this paper are often categorised as the work of a 'colourist' since they are painted with heightened colour, that is, with bright, intense or saturated colour. But the word 'colourist' is something of a variable term. To some it is almost derogatory in the sense of 'only being a colourist' as if it is a simplistic methodology whilst others use the term to merely describe the use of heightened colour without reference to the methodology or philosophy behind it. The reality is that colour is used as a means of expression to transform the sensations received from nature into a painting, that is, to transform input into output. This expression is based on a complex interaction of perception, emotion, the practice of painting, non-imitative colour, colour theory and the need to make a painting.

The paintings under discussion are part of a practice that comprises abstract, landscape, still life and figurative works. In addition, the practice includes printmaking consisting of some etching but primarily digital prints. For the digital work, the image is always constructed from a blank screen and never from imported images as a reaction against the facile use of filters such as found in Adobe $^{\circledR}$ Photoshop ${ }^{\circledR}$ to transform poor imagery into poor prints as evident in certain digital printmaking; the methodology is, therefore, analogous to that of painting. A range of work can be viewed at the author's online gallery [1].

This paper examines only landscape paintings, because they are examples of work produced in direct response to the stimuli received from nature and their transformation into a composition and as such, they demonstrate the effect and result of the sensations from nature. These paintings are the result of a studio practice, where these sensations from nature, captured in sketching, photographs and visual memory, are synthesised into a composition on canvas or board.

The predominant medium is acrylic paint although some work is in water colour, oil or pastel. Acrylic paint is a medium that offers good flexibility and allows for working in a variety of techniques.

All photographs in this paper were taken by the author unless otherwise stated. The progressive photographs are the result of studio shots and were taken as a record of the development of the paintings and were not originally intended for publication.

(C) 2009 WIT Press, www.witpress.com

ISSN: 1755-7437 (paper format), ISSN: 1755-7445 (online), http://journals.witpress.com

DOI: 10.2495/DNE-V4-N3-219-227 


\section{THE METHODOLOGY OF PAINTING}

How do these sensations from nature, the total input of colour, form, smell and sound come to be transformed into a painting? It is simply an emotional response to the sensations received from a particular motif: something in what is seen must stimulate a reaction. The painting is a response to God's creation in all its varied forms, its glorious colour and vitality giving a spiritual dimension to the work. The particular motif in a landscape that attracts such attention can be the shape or colour of a field or a group of trees or a building, etc. The whole painting is then established around that motif.

Well-meaning people will indicate the location of what they consider to be a beautiful landscape that 'must' be painted. But when examined, it elicits little interest and does not result in any emotional response. Indeed, it is more likely that if there was a rusty oil drum sitting by the road it would be seen as more interesting and worth sketching! What is essential is that the sensations received from a motif must result in an emotional response. This emotional response will be strong enough to sustain the considerable time necessary to examine the landscape and potentially produce many versions of artwork in order to develop ideas and produce a final painting.

The emotional response does not mean that the paintings are a simplistic portrayal of feelings but rather one scene or view is selected over others because, the sensations from that scene provoke the response. The emotions triggered vary considerably, such as, excitement, exhilaration, joy or passion with a motif as it is mentally transformed into a painting and the colour interrelationships are contemplated and subsequently developed in practice.

Matisse reduced his work to essentials [2], finding an equivalence of the painter's perception of nature, which did not reproduce what he saw but transfigured it. He translated the tonal values of the colours he saw into heightened colour of the same relationships. The paintings described here do not follow that system, and as a result, this work, whilst having a stability also has a dynamism in which perspective may be distorted, or the interrelationships of elements may be changed in the composition. For example, the de-saturation or lightening of the colours of distant objects to give the effect of aerial perspective is often deliberately not undertaken in order to maintain overall stability when painting with heightened colour (Fig. 1c, Meopham).

Nature is not slavishly copied but the sensations are submitted to the necessity of making a picture. The aim is to bring the compositional and colour elements into a unity over the whole surface to achieve stability. Within the stability there may be local areas of discord that are brought into balance over the whole composition. Thus, the use of colour is a construct, it is a means of expression, but not in the sense of attributing meaning to certain colours but simply as an expression of the emotional response to a landscape, the sensations from nature.

The attempt to achieve stability of the paintings involves a complex interaction of composition, colour and a sense of integrity. The composition has to be constructed, such that, it conveys an idea of place, that is, a particular landscape, not in a sterile manner but incorporating a dynamic structure and in such a way that the composition occupies the space of the canvas in equilibrium. Stability of colour is achieved by balancing hue, saturation and lightness throughout the painting. However, balance is not a question of everything fitting with everything else, since as Arnheim [3] rightly stated, this represents 'the most primitive kind of harmony, suitable at best for the colour schemes of nurseries and baby clothing'. The stability is achieved through the integration of the different colour components in the painting: the disharmonies that are in balance only in the context of the whole; the small isolated touches of colour that relate to displaced colour; the areas of serenity and of agitation; the juxtaposed complementaries or dissonances. Thus, the colour balance is complex and includes the painting as a whole, there are not inessential or redundant parts. 
(a)

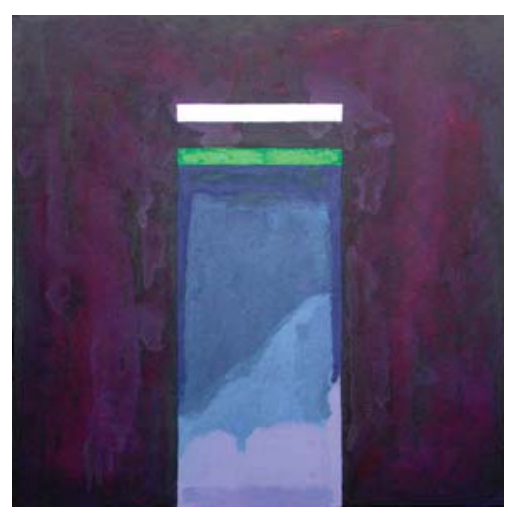

(c)

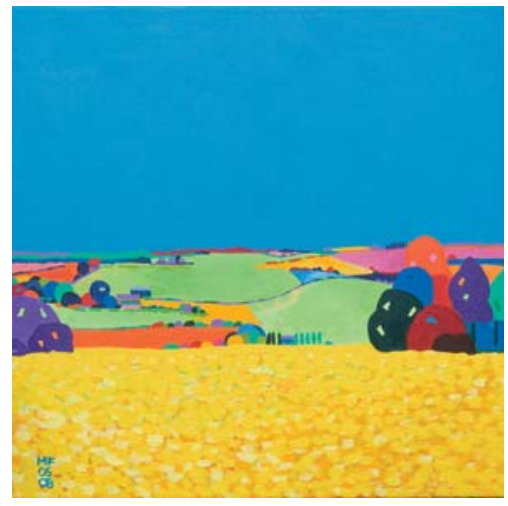

(e)

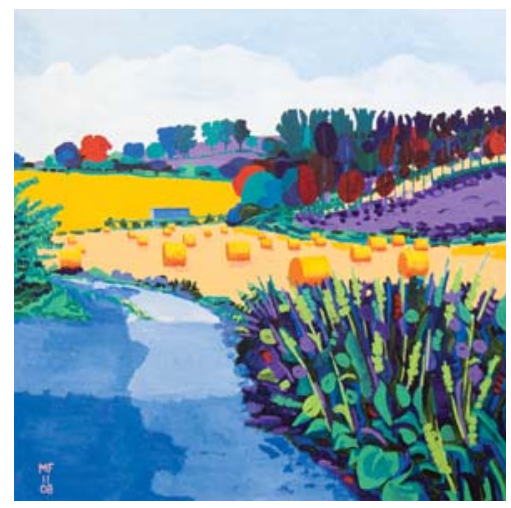

(b)

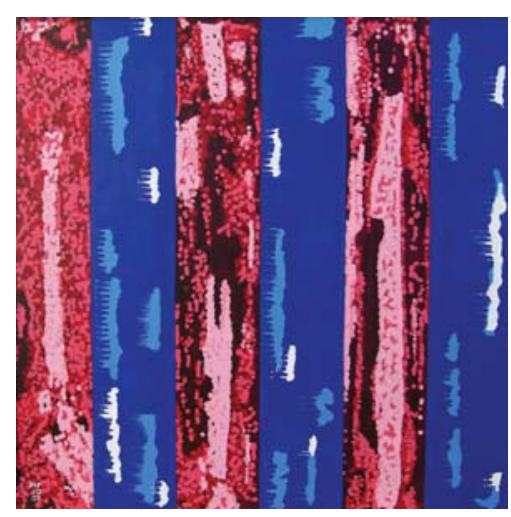

(d)

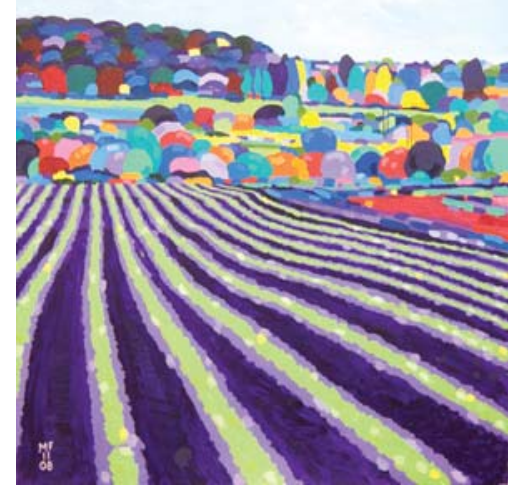

$(\mathrm{f})$

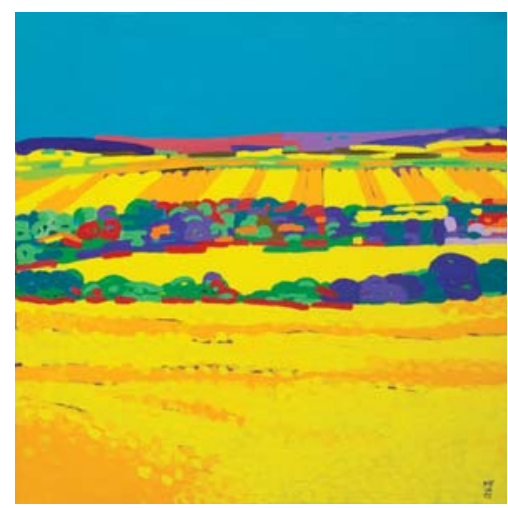

Figure 1: Examples of abstract and landscape paintings. (a) Day 1 from Days of Creation $(600 \times 600$ $\mathrm{mm}$, acrylic on board). Photo by Tanya Uroda. (b) Day 3 from Days of Creation $(600 \times 600$ $\mathrm{mm}$, acrylic on board). Photo by Tanya Uroda. (c) Meopham $(50 \times 50 \mathrm{~mm}$, acrylic on canvas). (d) Farm 2 (Cliffe) $(500 \times 500 \mathrm{~mm}$, acrylic on canvas). (e) Harvest (Betsham) $(500 \times$ $500 \mathrm{~mm}$, acrylic on canvas). (f) South Darenth $(800 \times 800 \mathrm{~mm}$, acrylic on canvas). 
The third aspect of stability is that of the sense of integrity which relates both to the composition and the use of colour. Each painting is executed after considerable thought and planning with sketches and investigations of composition and colour before the final version is realised. Hence, the paintings are not accidental, unfinished or meretricious, but seek to have a stability, such that the paintings maintain validity through time.

Examples of some paintings can be seen in Fig. 1, which shows two abstracts and four landscapes. Day 1 (Fig. 1a) and Day 2 (Fig. 1b) show two paintings from a series of seven on the days of creation. These works are painted with very dilute paint that is poured on the board and allowed to dry for different times, at certain stages tissue paper is pressed onto the paint and pulled off leaving a 'print-like' texture. The layer of paint is very thin and the technique allows the build-up of many layers producing a rich depth of colour. Figure $1 \mathrm{~b}$ has the added technique of spotting paint onto the board to give highly opaque dots. This style of painting has been developed over a number of years and is referred to as 'abstract graphism', whereby a written text or emotion is represented by graphical and colour elements that can be 'read' to discover the underlying meaning.

Figure $1 \mathrm{c}-\mathrm{f}$ show various landscapes on canvas, $\mathrm{c}$. and $\mathrm{f}$. both have their sky in flat phthalocyanine blue and d. and e., the latest paintings shown here, have a more complex sky in different tones of blue with clouds. All four landscapes are the result of experiments exploring the fusion of landscape with abstraction such that compositional elements may be greatly simplified. For example, many of the trees in South Darenth (Fig. 1f) comprise interwoven lines or curves rendered in different hues and tonal values; it is evident that they are trees from the context. In all four of these landscape paintings, some elements such as trees or fields are painted in flat colour, again, to simplify the composition and allow the colours to resonate with little reference to their form.

Why use heightened colour, why not use pastel colours rather than highly saturated colours that have such a strong impact? The hues used in these paintings are common to many painters but they are highly saturated which gives them an intense purity so they have the clarity to express emotion in the desired way. With anything less, the emotion would become diluted and would not represent the true response to the sensations from nature and so the paintings would lack integrity. These saturated colours resonate with each other in a lively and dynamic way that best expresses that emotional response.

The colours are not copies of nature and are therefore, used with purpose; if a sky is red or green then it is because it creates the desired stability, and as Matisse [4] said: 'When I use a green it doesn't mean grass; when I use a blue, it doesn't mean the sky' thus, if a sky is painted blue then that particular blue is important, not because sky is often blue. In the author's recent work skies have been simplified to a uniform phthalocyanine blue to allow the landscape to speak without hindrance or competition. At present some paintings still have skies of uniform blue but some move from this and go back to having clouds (Fig. 1e), and in the future some may have skies coloured red or green; for the present this uniformity of colour is being explored.

Bruce et al. [5] discuss the way the world around us is perceived. They describe the way our eyes scan the surrounding scene so that our gaze is directed to points of interest. These scans are called Saccades and are very rapid movements of the eyes up to $500 \%$ s. The saccadic scanning allows analysis of those parts of the scene by the fovea, a small central area of the retina rich in cone photoreceptors providing high acuity vision in bright light. Bruce et al. describe sampling of the optic array as occurring in three ways: first, saccadic scanning of the scene to fixate objects with foveal vision; second, with 'pursuit' movement to keep objects in foveal vision as they move; and, finally, 'convergence' movement to maintain foveal vision of both eyes if distance to the scene changes.

Saccades are sudden and intermittent whilst 'pursuit' and 'convergence' movements are smooth and continuous. So when viewing static paintings the information input is primarily by saccadic scanning of the painting. Yarbus in the 1950s-1960s recorded the eye movements of subjects as they 
looked at paintings and found that they looked mostly at high contrast areas, fine detail areas and areas with human or biological interest. He found [6] that saccades were in response to viewing strategies such as examining a painting to answer specific questions about the content or to simply examine the painting. Yarbus has been criticised for his methodology which was intrusive and may therefore have distorted the results but recent experiments by Lipps and Pelz [7] confirm the task dependency but with a less dramatic effect.

Saccadic scanning has important implications for the painter. So often we read or see on television documentary art programmes supposedly erudite critics examining a painting and describing how the painter 'leads' the observer's eyes around the composition. While this might sound plausible and represent received opinion, the studies of saccadic scanning indicate that a least, a priori, the viewing of a painting does not necessarily follow the composition, but occurs in the observer a posteriori, after information input when compositional elements are recognised and can be understood [8].

The paintings described here aim to have an overall balance of colour but have local areas of dissonance. These are placed in the painting to add a dynamic structure to the composition and to act as visual 'traps' when the image is examined using saccadic scanning. Hence, by using unexpected hue and tonal combinations, the eye is fixated as it scans the painting so that the observer will perhaps be surprised by compositional elements, have a greater information input and therefore, a better understanding of the painting.

This can be seen in Fig. 1c, Meopham, where pyrrole orange is juxtaposed with permanent rose (quinacridone) on both left and right near the horizon to give perhaps an unexpected colour contrast. Further examples can be seen in Fig. 3f, Bridges of London, where the pale pyrrole orange of the Post Office Tower in centre horizon and the light green (phthalo green and hansa yellow) building to the left horizon stand out in high contrast to the phthalocyanine blue sky. In addition, there are a number of buildings painted with alternating light and dark horizontal bands that give striking visual impact.

Of course, compositional elements that may be described as effectively 'leading' the eye are present in these paintings but these are designed to give a stable structure to the painting not to lead the observer. Indeed, although colour is extremely important in these paintings, composition is regarded as being of greatest importance and therefore, above the use of colour.

\section{THE METHODOLOGY OF USING COLOUR}

How is one colour placed against another? It is like a puzzle in many dimensions, about contrast and complement, about harmony and how it fits with the composition, about mood and excitement. Paintings are often worked in phases of colour, adding touches of the same colour to different places on the canvas, always checking the result. Each colour must be put down in relation to the other colours with consideration for how they work together and what feeling or expressiveness is given. Underlying this there is strong theoretical basis, but it is not painting in theory but instinct. If the sensations from nature evoke an emotional response that results in a painting, then the painting has to be instinctive, without stopping to think through some aspect of colour theory; if this happened, then the painting would become sterile and stifle the sense of emotion. With years of practice there is enough experience to know instinctively what colour goes with what to produce the desired effect to free the process of painting from such sterility.

The theoretical basis relies on the use of complementary colours that are juxtaposed, next to or near each other and those displaced in different parts of the painting [9]. Thus, the complementary colours interact in different ways depending on their proximity with both local and displaced interactions giving local and overall stability. In addition to the complementary colours, those close to each other in hue are placed together (such as pyrrole orange and quinacridone), that is, those hues 
adjacent or near adjacent on the colour wheel [9] in order to produce areas of local dynamic colour interaction that lack harmony. Itten [10] described colour harmony in geometric terms in relation to the colour wheel, whereby combinations of hues would be harmonious if when mixed they yielded grey-black such as opposite hues (that is, a primary and secondary hue, being a mixture of all three primaries). But two adjacent hues would lack the geometric opposites and so not yield grey-black when mixed. Such dissonances constitute part of the 'visual traps' described earlier.

\subsection{Progressives}

In order to show the methodology of painting, two series of 'progressives' are given in Fig. 2 and Fig. 3 that show the development of two paintings: Bridges of London (acrylic on canvas, $800 \times 800$ $\mathrm{mm}$ ) and Grubb Street (acrylic on canvas, $800 \times 800 \mathrm{~mm}$ ). These photographs are the result of 'snapshots' taken in the studio often under poor lighting and were not originally intended for publication.

\subsubsection{Grubb Street}

Figure 2a-e show the stages of painting the landscape Grubb Street (a small village in North Kent) and Fig. $2 \mathrm{f}$ shows the finished painting in the same scale. Some stages show that colours are changed as the painting develops, this is either because one colour is used as under-painting for another or to define edges clearly or because adjustment is needed during the execution of the work as more colours are seen to resonate with each other. In Fig. 2a, dioxazine purples and reds (quinacridones) are added; notice that the tonal value of the purples are the same in the foreground and background. In Fig. 2b, there is the addition of light greens (phthalo green and hansa yellow) and lighter purples giving a simple interaction of secondaries that are either juxtaposed or displaced. Figure $2 \mathrm{c}$ shows the laying in of foreground greens (phthalocyanine greens and hansa yellow) with course stippling (naphthol green, phthalo green, bismuth yellow and cadmium yellow) and the development of mid-ground trees in purples and blues (cobalt blue, phthalo turquoise blue and cobalt blue cerulean) and the purple stripes of the mid-ground field.

In Fig. 2d, the first layer of the sky (phthalocyanine blue) is painted and mid-ground and distant purples; note that the distant purple is darker than the mid-ground trees to give the correct stability in relation to the blue sky and the purples and reds of the distant hills and fields. This is, therefore, contrary to ideas of aerial perspective. Figure 2e shows the nearly completed painting with the laying in of greens, yellows, oranges and reds. This includes the bright green field on the left to centre distance and an orange line (pyrrole orange) centre right of distance to resonate with the bands of purple, permanent rose and quinacridone violet. The final painting in Fig. $2 \mathrm{f}$ indicates that the drawing is adjusted by reducing the height of the right-hand tree, the remaining far-ground trees and fields are completed and the sky has three more layers of blue added.

\subsubsection{Bridges of London}

Figure $3 \mathrm{a}-\mathrm{e}$ show the stages of painting the landscape Bridges of London (a view looking up-river from Tower Bridge); the final work is shown in Fig. 3f. Again some colour changes are evident for the same reasons as described for Grubb Street above. Figure 3a shows the laying in of the blue sky and the phthalo green, pyrrole red and pyrrole orange base colours for the river. In Fig. 3b, dioxazine purples and reds (alizarin crimson) are added for some of the buildings and boats, and the river is developed by adding stippling of reds and oranges in different tones. Figure $3 \mathrm{c}$ shows the laying in of light greens (phthalo green and hansa yellow), light blues (phthalo turquoise blue and light reds) 
(a)

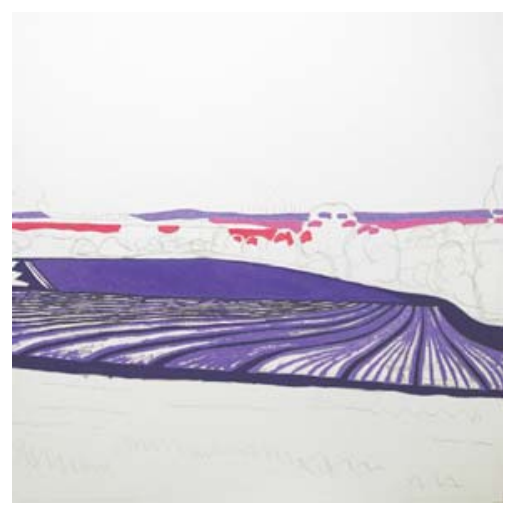

(c)

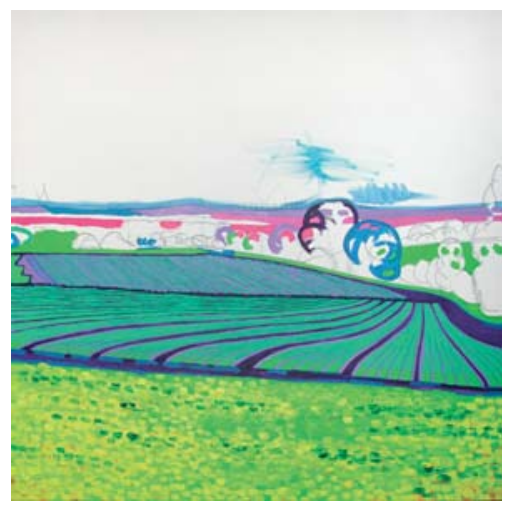

(e)

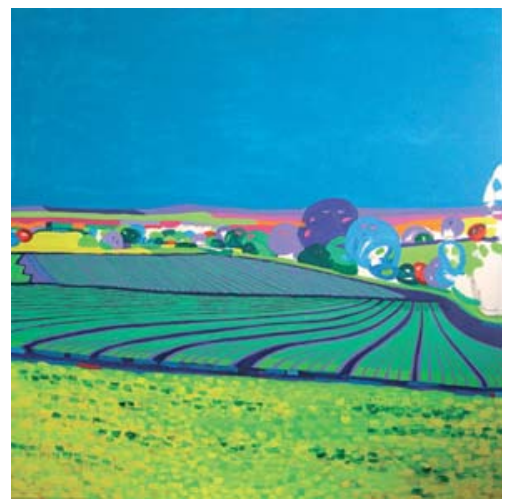

(b)

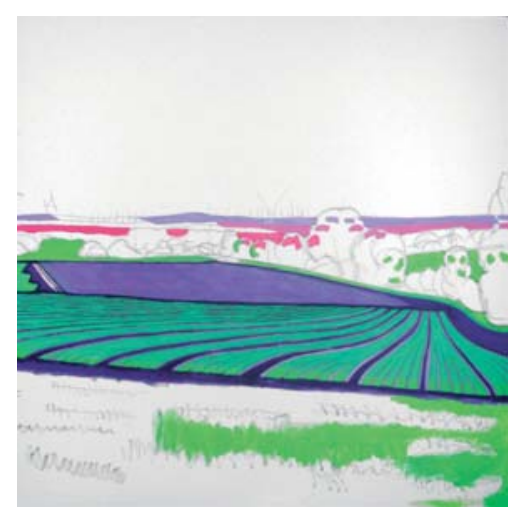

(d)

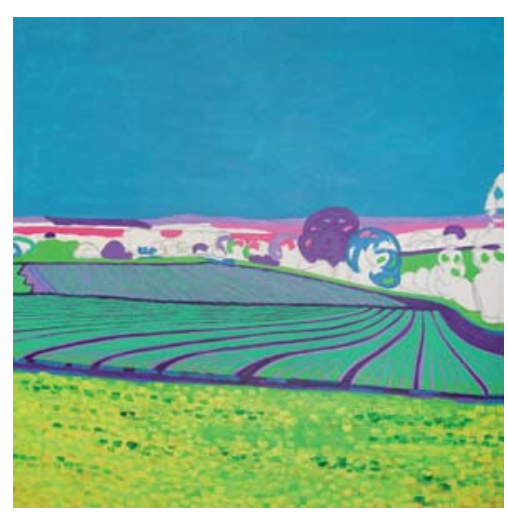

(f)

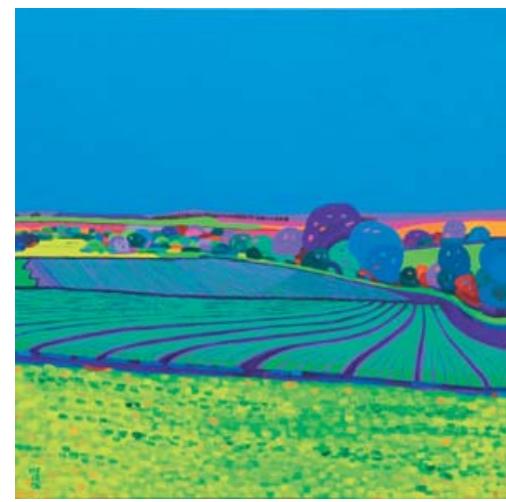

Figure 2: Progressives for Grubb Street $(800 \times 800 \mathrm{~mm}$, acrylic on canvas). (a) Laying in of purples and reds in foreground and background. (b) Addition of greens and lighter purples. (c) Laying in of foreground greens and development of midground. (d) Laying in of blue sky and midground purples. (e) Near completion with laying in of greens, yellows and reds. (f) Reduction in height of right tree and completion of painting. Photo: Ian Goodrick Photography. 
(a)

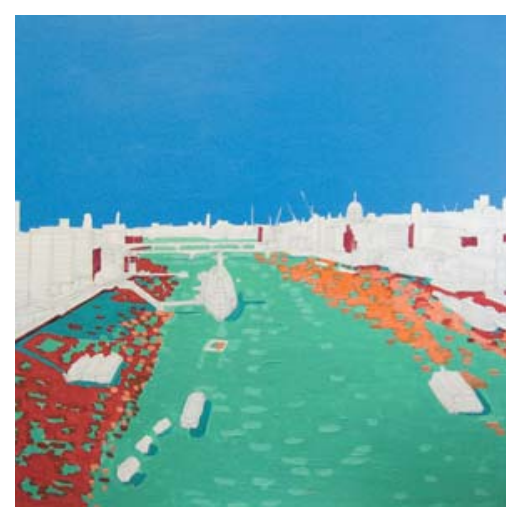

(c)

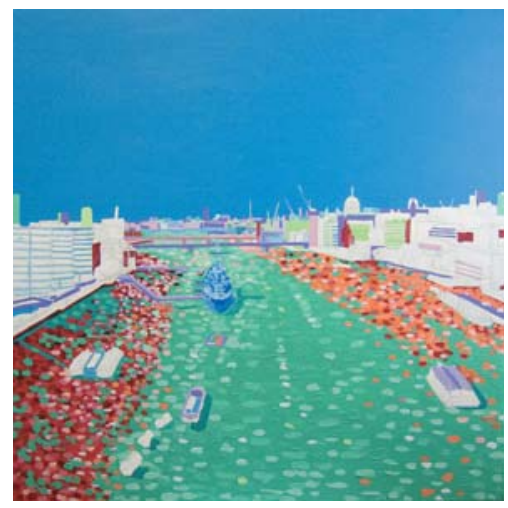

(e)

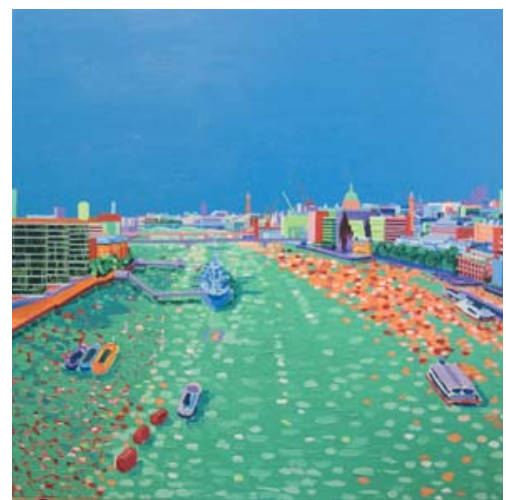

(b)

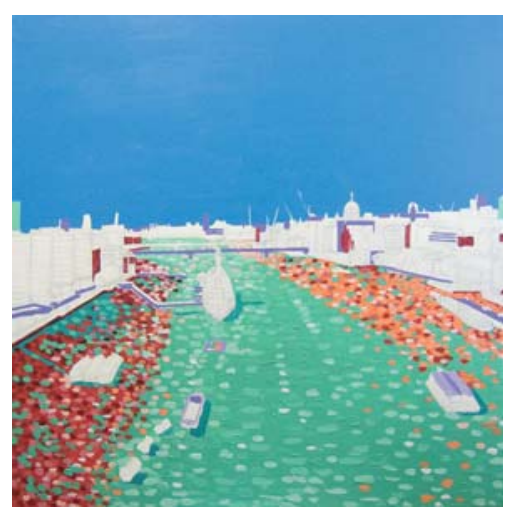

(d)

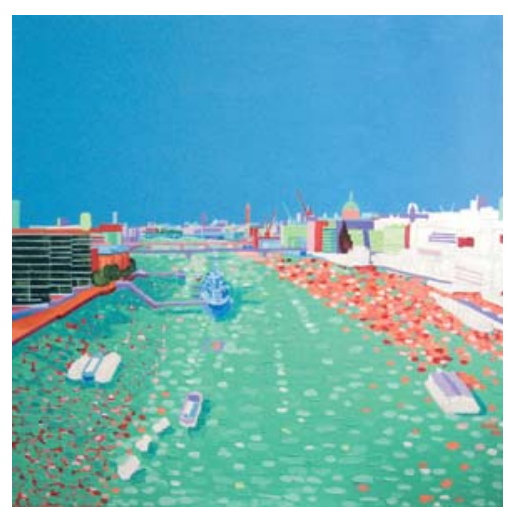

(f)

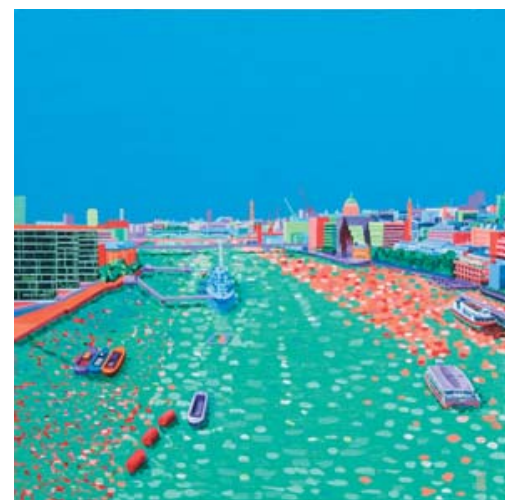

Figure 3: Progressives for Bridges of London $(800 \times 800 \mathrm{~mm}$, acrylic on canvas). (a) Laying in of blue sky and green, red and orange base colours for river. (b) Laying in of purples and reds for buildings and development of river. (c) Laying in of light greens and reds of buildings and blues on ship. (d) Laying in of dark greens and reds for buildings and further work on river. (e) Near completion of buildings and rough blocking in of boats. (f) Showing completed painting. Photo: Ian Goodrick Photography. 
to give form to some of the buildings and the basic painting in phthalocyanine blues of the ship (H.M.S. Belfast). Figure 3d shows the laying in of dark greens (cadmium green deep) and reds (alizarin crimson and pyrrole red) for the buildings and further work on the river. In Fig. 3e, there is the near completion of the buildings and the rough blocking in of the remaining boats. Figure $3 \mathrm{f}$ shows the completed painting with some adjustments to tonal values.

Before commencing a painting the composition and arrangement of colours is usually resolved using sketches, watercolour thumbnails or small works in acrylic, but most of the planning is undertaken mentally. This is so that when the final composition is started it can be painted with minimal hesitation to maintain a dynamic but stable structure. Of course, sometimes an idea may seem to work as a mental image but somehow not on canvas and sometimes, after laying down a particular colour its effect on other colours produces unforeseen effects so that adjustment is needed. Adjustment may also be required in the underlying sketch of a painting as it progresses because the compositional elements may not be as stable as at first thought; this can be seen in Fig. 2e-f.

The completion of a work can take on a near iterative process with small adjustments being made all over the surface. And upon 'completion' the painting is put aside for several weeks so that it can be re-examined later with a fresher view and understanding of the composition. Sometimes a painting is left for a considerable time, perhaps a year; the longest has been ten years after which the sky of a landscape was reworked to improve overall stability.

\section{CONCLUSION}

The aim of this paper is to give some understanding of how a sensation from nature is translated into a finished painting with overall balance and stability, allowing for local areas of dynamic dissonance. Nature is not copied but the sensations are synthesised into a composition constructed on canvas. The work is based on an emotional response to the received stimuli with the hope that the paintings are seen as thoughtful but instinctive, show integrity and stability, and are never trivial and never ephemeral.

[1] The website of Mike Fryer: www.mikefryer.co.uk

[2] Flam, J. (ed), Matisse on Art, University of California Press: Berkeley and Los Angeles, California, 1995.

[3] Arnheim, R., Art and Visual Perception: A Psychology of the Creative Eye, The New Version, University of California Press: Berkeley and Los Angeles, California, 1995.

[4] Ferrier, J.-L., The Fauves, the Reign of Colour, Finest S.A./Éditions Pierre Terrail: Paris, 1995.

[5] Bruce, V., Green, P.R. \& Georgeson, M.A., Visual Perception, Physiology, Psychology, \& Ecology, 4th edn, Psychology Press: Hove and New York, 2003.

[6] Yarbus, A.L., Eye Movement and Vision, Plenum Press: New York, 1967.

[7] Lipps, M. \& Pelz, J.B., Yarbus revisited: task-dependent oculomotor behavior. Journal of Vision, 4(8), Abstract 115, 2004.

[8] Livingstone, M., Vision and Art: The Biology of Seeing, Harry N Abrams, Inc.: New York, 2002.

[9] Fryer, M.J., Complementarity. Optics and Laser Technology, 38, pp. 417-430, 2006. doi:10.1016/j.optlastec.2005.06.003

[10] Itten, J., The Elements of Colour (translated by E. Van Hagen), Chapman and Hall: London, 1970. 